\title{
Educational Re-engagement as Social Inclusion: the role of flexible learning options in alternative provision in Australia
}

\author{
GEORGE MYCONOS, JOSEPH THOMAS, \\ KIMBERLEY WILSON, KITTY TE RIELE \& LUKE SWAIN
}

\begin{abstract}
In Australia, a significant minority of young people do not complete upper secondary education. Whether procedural or enacted through the agency of students, the failure of the education system to accommodate young people through to completion can be regarded as a form of institutionalised social exclusion and injustice. In response, a growing number of flexible learning options (FLOs) are providing marginalised young people with alternative avenues for meaningful educational reengagement. The authors of this article examine two key characteristics of FLOs: an unconditional acceptance of young people, and the integrated well-being support upon which inclusion is premised. Their discussion draws on in-depth interviews conducted with students and practitioners at a diverse range of sites. They find that FLOs play a key role in the process of re-inclusion, but this contribution to reducing social and educational inequality is predicated on a level of well-being support not ordinarily available in mainstream schooling.
\end{abstract}

\section{Introduction}

Notwithstanding a range of state and federal government interventions to prevent disengagement from schooling, many young Australians do not complete secondary education (Australian Bureau of Statistics [ABS], 2015). While Australia has made recent gains in terms of aggregated upper secondary ('Year 12') attainments, there remains a significant achievement gap between those of the lowest and highest socio-economic backgrounds. Indeed, only around $60 \%$ of students of the lowest socio-economic status decile complete 
Year 12 by age 19 in Australia, compared to $89 \%$ of those in the highest decile (Lamb et al, 2015).

Disadvantaged young Australians face complex barriers to integration within mainstream schooling (Campbell et al, 2012). These challenges are myriad and intersecting, but include, inter alia, interrupted schooling, low literacy and numeracy, learning disabilities, anxiety and depression, substance misuse, socio-economic insecurity, physical insecurity and youth justice involvement. Specific groups - including young people in the care of the state, young parents and carers, LGBTIQ youths and Indigenous young people experience radically lower levels of educational attainment and school completion (KPMG, 2009; Purdie \& Buckley, 2010; COAG [Council of Australian Governments], 2013; Lamb et al, 2015).

Neo-liberal market imperatives permeate the Australian educational landscape, pitting student against student, school against school, state against state, and private interest against public good. In a process of residualisation, socioeconomically advantaged young people are gravitating in ever greater numbers to the nation's heavily subsidised private-independent school sector, while students from low socio-economic backgrounds are concentrated in Australia's chronically underfunded public school system (Masters, 2016).[1]

The marketisation of education in Australia - couched in terms of parent and consumer choice - has also impelled school leaders to pursue institutional competitive interests (Connell, 2013). Indeed, greater devolution of enrolment authority to schools has allowed school administrators considerable personal discretion to 'exit' low-achieving students from school rosters. To promote their institution's status, heads of schools increasingly jettison underperforming students into 'alternative educational settings' (Brader \& McGinty, 2005; De Jong \& Griffiths 2006; Te Riele, 2014), commonly described in the United Kingdom as 'alternative provision' or more colloquially as 'exclusion units'. This is a clear manifestation of social exclusion.[2] Notwithstanding this fundamental injustice, young Australians are being granted novel opportunities for selfactualisation through participation in alternative schooling programs known as flexible learning options (FLOs).

This article offers a glimpse into the ways needs-tailored FLOs reduce social and educational inequality and enable the educational 're-engagement' of marginalised young Australians. Some 900 FLOs now provide educational reengagement opportunities for nearly 70,000 of Australia's most severely disenfranchised young people (Te Riele, 2014). Approximately one-third of FLOs comprise autonomous, community-based, and non-school programs (Wilson et al, 2011; Te Riele, 2012a; McGregor et al, 2014). These sites are not just physically located outside conventional high schools - they also work in unconventional ways that provide young people the freedom to get on with their learning. Our focus turns here to two central characteristics of FLOs their unconditional acceptance of marginalised young people and the central role of integrated well-being support - in order to examine these programs' re- 
engagement of marginalised youths as a process of (re)inclusion and restorative social justice.

This article is one outcome of a nationwide research project on the impact of FLO participation for individuals and the broader Australian community. The central research questions for the project as a whole were:

1. What life trajectories (and their associated individual and societal outcomes) do disengaged young people traverse in the Australian context?

2. What changes to these life trajectories (and associated changes to individual and societal outcomes) can be expected as a result of participation in Flexible Learning Options?

3. What mechanisms are at work in Flexible Learning Options that facilitate the reshaping of life trajectories of disengaged Australian young people?

This article is based on in-depth interviews with 57 students, 22 teachers and 25 support staff at five FLO sites in Victoria, Queensland and Western Australia.[3]

\section{Inclusion through Unconditional Acceptance of Young People}

All the programs studied have as their raison d'être a commitment to assist those needing a 'second chance'. Eligibility protocols commonly required estrangement from (or by) previous schools, along with evidence of individual and social hardship. Student interviewees conveyed manifold antecedents to their disengagement and clearly expressed the ways mainstream schools curtailed their freedom to learn and failed to address their complex array of needs:

I couldn't understand because I have a bunch of issues. My medical disabilities [meant] I could not do it. I have fibromyalgia and ADHD [Attention Deficit Hyperactivity Disorder]. In the end most of my schools, I actually left because of bullying. I just couldn't do it. I was the only one that had disabilities. [Everyone else] just looked like normal kids. (Austin, student, Site E)

It just came to the point that what I needed and the school could provide did not meet. I needed teachers that could change their ways for me, and a whole bunch of more like me. They couldn't. They wouldn't. Does that mean I failed? I did fail. But, really, no, I think school failed. I wanted to learn, but they couldn't do it in a way that suited what I needed. (Jasmine, student, Site C)

Of his 'mainstream' school experience, Riley (student, Site A) suggested that teachers 'just ignore you and go help someone else that's "worthwhile".

The FLOs researched ensured each young person 'counted' and was made to feel 'worthwhile', a radical alternative to the pedagogical approach of the young people's previous mainstream schooling experiences. FLOs made explicit 
reference to unconditional acceptance - in Carl Rogers' (1969) terms, 'unconditional positive regard' - in their vision statements, based on the right of all young people to have the freedom to be themselves and to learn. Unconditional acceptance was enacted through routine practices characterised by strengths-based, non-punitive and non-judgmental relationships, as well as patience and stability: 'They've [heard] in mainstream schools that they are losers, or that they are too hard, or that they are not worth the teacher's time' (Kim, staff, Site A). In contrast:

We meet them where they're at ... it's that idea of that acceptance or that appreciation that you need a little bit of extra care to be able to get your education ... This is a place where we're not going to get angry at you for having a new tattoo or having another piercing ... . You can turn up in tears, you can turn up having self-harmed, you can turn up just however you want - drunk, alcohol-affected - we will welcome you. But we will sort you out. (Jo, staff, Site A)

(Re)inclusion within the FLO context is predicated on students' autonomy and personal agency. By consistently acting on principles of acceptance and inclusion, FLOs ensured young people also championed such principles themselves:

I think everyone knows this place is different and there are rules, like principles, and if you come, you've got to live by those ... . Live by the principles. Everyone wants to be here because of that, like, it's fair. (Connie, student, Site C)

Several teaching and administrative staff remarked that their programs are most effective when students retain control over their participation. For many students - in particular those with a history of school-related disciplinary action and antagonistic interactions with authority figures - this proactive empowerment of students constituted a radical point of difference between the FLO and their mainstream schooling experience. Unconditional acceptance by staff was the foundation for students' freedom to learn.

\section{The Central Role of Integrated Well-being Support}

However, we learnt from our interviews that unconditional acceptance does not, in itself, suffice. All of the FLOs studied also clearly emphasised policies and practices that privileged well-being support for young people. It is evident that providing students with support and sustenance - social and emotional, as well as physiological and material - is critical to processes of inclusion and reengagement.

Staff reiterated the hardship experienced by students outside of the educational environment, as well as the scale and complexity of students' needs:

Many come from homes where it's second or third generation

welfare. They have parents that have got drug or alcohol issues. 
Some of them have homelessness issues, so they're constantly in that state of being unstable in their home life. (Sophia, staff, Site A)

The importance of social and emotional well-being, stability, and security was made plain by students, who had felt unsupported by staff and threatened by peers in mainstream schools. One student suggested, 'Teachers would get angry at students who left the class to go see the councillor' (Julie, Site A), and others expressed concern about the ways in which schools triaged 'good reasons' for granting access to well-being support services (Mark and Peta, class discussion, Site A). Whilst most educational institutions do have some policies and protocols to address students' basic needs, in the FLOs, well-being support was embedded in everyday practice as a defining - and distinguishing - component of their alternative approach:

In a lot of mainstream schools, the educational part will come first. That doesn't come first here. It's that the whole child will come first, because if that whole child's not comfortable and positive or not feeling confidence, they're not going to be able to get through their schoolwork. (Anna, staff, Site C)

While mindful of the ways in which 'therapeutic education' and 'social and emotional learning' have been incorporated within a productivist human capital agenda (Ecclestone et al, 2009, p. 3), our interviewees left little doubt as to the vital role of well-being support for facilitating an environment in which students were enabled to be free: to be themselves, and to get on with learning. In many cases, staff in these often under-resourced programs responded to students' poverty, ill health or homelessness by linking students to external supports and specialists:

A lot of them don't know how to access services, so at least if we have a well-being worker in each class they can say, 'Okay, we can connect you with housing service ... we can connect you with drug and alcohol workers, we can put you in detox' ... we can take them to Centrelink [for youth welfare payments]. (Bryan, staff, Site B)

Additional well-being support mechanisms included provision of transportation, referrals for physical and mental health services, and to legal assistance - a suite of responses to ameliorate student hardship in practical, immediate ways. Thus the process of inclusion entailed not only resumption of a stalled education, but also connections to wider networks of support beyond the educational setting. Locating the 'social' centrally within 'education' sums up the approach of these FLOs to 'socially just education'. Addressing students' myriad well-being issues was seen by staff as a necessary precondition for educational engagement, inclusion and, ultimately, progress. Above all, interviewees emphasised the importance of supportive relationships between students and staff: 
The teachers here are more caring and more interested into people's problems ... they're just respectful ... they're just lovely and kind and caring. (Grant, student, Site C)

Staff devoted considerable time to engendering a sense of trust, patience, understanding and respect. This is no easy task given that upon arrival to the FLO, students commonly displayed a hyper-vigilance born of fear and vulnerability. This resonates with the findings of Smyth et al (2010) and Lange and Sletten (2002), with the latter claiming that school suspensions, missed classes and academic failure leave many disenfranchised young people "weary of the school experience and distrustful that the education system can be a tool for their success' (p. 11).

Staff also reported working with students to improve their peer relationships. This is noteworthy, not least because FLO participants commonly identify negative experiences with peers as key triggers of their initial disengagement (Te Riele, 2012b, p. 44; Thomson, 2014). With re-engagement in the flexible learning space consciously rooted to students' sense of safety, mutual support and belonging, the metaphor of 'family' was common across most of the sites:

It's just like one big family. Any new kid is always welcome. We accept everyone. Who they are, where they come from ... doesn't really matter. We see them as a person ... We don't judge them by how they look or what they do. We judge them from the inside from what they want to share ... After a while, you realise it's a great family. I love being here. There's all this love and warmth everywhere. (Sarah, student, Site B)

In this context, the FLOs assumed the role of a haven, with our findings affirming research (Noddings, 1992; Mills \& McGregor, 2010; Davies et al, 2011; Te Riele, 2012a, b, 2014) suggesting that young people experience empowerment as 'subjects of care' in these educational programs.

\section{Conclusions}

FLOs exist not only at the margins of traditional education, but at a crossroads of 'mainstream' schooling, community-based education, vocational training, and public and non-governmental support services (Myconos, 2014, p. 8). Alternative settings represent a 'diverse and shifting patchwork of connections and disconnections with mainstream education' (Kraftl 2015, p. 238) - and, we would add, extend their reach into the broader society from which young people are increasingly estranged. After exclusion by the 'mainstream', the freedom of a young person to make independent decisions and act purposefully is significantly curtailed, and requires a transitional phase wherein the young person's challenges and fears are allayed within stable, supportive settings. 
Our findings suggest that the two mechanisms of social inclusion referred to in this article are integral to achieving success for young people experiencing complex life circumstances and concomitant difficulties in their education. While mainstream schooling systems may consider the complex needs of disenfranchised youth as being located outside of their general remit - an orientation magnified within a highly competitive neo-liberal educational agenda - the ethics of socially just schooling impel consideration of any elements of education that might be systematically working to exclude those most at risk. It is thus necessary to consider how 'the alternative practices of flexible learning centres [could] be supported as models of effective teaching and be used to inform practices within mainstream schools' (Mills \& McGregor, 2010 , p. 10). The suggestion of this article is that the mechanisms of 'unconditional acceptance' and the provision of 'holistic well-being support' are important considerations in reshaping educational spaces to better fit students, rather than attempting to mould diverse youth into the form of schools. Implementing such mechanisms in mainstream schooling may well prevent marginalised students from having to transfer to alternative settings, as well as better serve their peers who stay behind - individuals neither fully excluded, included, nor free to learn.

\section{Acknowledgement}

This research was supported under the Australian Research Council's Linkage Projects funding scheme (Project ID:LP130100344).

\section{Notes}

[1] Students from socioeconomically disadvantaged areas comprise over $30 \%$ of enrolments of government schools, with only $9 \%$ within what are regarded 'Independent' (see Connors \& McMorrow, 2015, p. 53).

[2] Residualisation is characterised by the interplay of a complex range of factors. See the Social Exclusion monitor, developed by the Brotherhood of St Laurence and the Melbourne Institute of Applied Economic and Social Research. The monitor assesses the relative impact of material resources, employment, education and skills, health, social connection, community and personal safety. https://www.bsl.org.au/knowledge/social-exclusion-monitor/

[3] For more information about the full project, see http://www.floresearch.com.au/

\section{References}

Australian Bureau of Statistics (ABS) (2015) 4221.0 Schools Australia.

http://abs.gov.au 
Brader, A. \& McGinty, S. (2005) Educational Disengagement: a review of international, Australian and state policy responses, in A. Pandian, M.K. Kabilan \& S. Kaur (Eds) Teachers' Practices and Supportive Cultures. Serdang: Universiti Putra Malaysia Press.

Campbell, L., Mcguire, M. \& Stockley, C. (2012) I Just Want to Go to School: voices of young people experiencing educational disadvantage. Good Shepherd Youth \& Family Services, Jesuit Social Services and Mackillop Family Services. http://www.mackillop.org.au/assets/325/1/i_just_want_to_go_to_school_report _digital.pdf

COAG Reform Council (2013) Skills in Australia 2012: five years of performance. COAG Reform Council, Sydney. http://www.coagreformcouncil.gov.au/reports/skills-and-workforcedevelopment/skills-australia-2012-five-years-performance (accessed 4 August 2016).

Connell, R. (2013) The Neoliberal Cascade and Education: an essay on the market agenda and its consequences, Critical Studies in Education, 54(2), 99-112. http://doi.org/10.1080/17508487.2013.776990

Connors, L. \& McMorrow, J. (2015) Imperatives in Schools Funding: equity, sustainability and achievement. Melbourne: Australian Council of Education Research.

Davies, M., Lamb, S. \& Doecke, E. (2011) Strategic Review of Effective ReEngagement Models for Disengaged Learners. Melbourne: Victorian Department of Education and Early Childhood Development. http://www.education.vic.gov.au/Documents/about/research/revreengage.pdf

De Jong, T. \& Griffiths, C. (2006) The Role of Alternative Education Programs in Meeting the Needs of Adolescent Students with Challenging Behaviour: characteristics of best practice, Australian Journal of Guidance and Counselling, 16(1), 29-40. http://dx.doi.org/10.1375/ajgc.16.1.29

Ecclestone, K. \& Hayes, D. (2009) The Dangerous Rise of Therapeutic Education. London: Routledge.

KPMG (2009) Re-engaging Our Kids: a framework for provision to children and young people at risk of disengaging or disengaged from school. Melbourne: Department of Education and Early Childhood Development.

Kraftl, P. (2015) Geographies of Alternative Education: diverse learning spaces for children and young people. Bristol: Policy Press.

Lamb, S., Jackson, J., Walstab, A. \& Huo, S. (2015) Educational Opportunity in Australia 2015: who succeeds and who misses out. Melbourne: Mitchell Institute. http://www.mitchellinstitute.org.au/reports/educational-opportunity-in-australia2015-who-succeedsand-who-misses-out/

Lange, C. \& Sletten, S.J. (2002) Alternative Education: a brief history and research synthesis. Research Report. Alexandria, VA: Project Forum.

Masters, G. (2016) Five Challenges in Australian School Education. Camberwell: Australian Council for Educational Research.

McGregor, G., Mills, M., Te Riele, K. \& Hayes, D. (2014) Excluded from School: getting a second chance at a 'meaningful' education, International Journal of Inclusive Education, 19(6), 608-625. http://doi.org/10.1080/13603116.2014.961684 
Mills, M. \& McGregor, G. (2010) Re-engaging Students in Education: success factors in alternative education. Research Report. Brisbane: Youth Affairs Network Queensland.

Myconos, G. (2014). Lessons from a Flexible Learning Program: the Brotherhood of St. Laurence Community VCAL education program for young people 2010-2013. Fitzroy: Brotherhood of St Laurence Community.

Noddings, N. (1992) The Challenge to Care in Schools, 2nd edn. New York: Teachers College Press.

Purdie, N. \& Buckley, S. (2010) School Attendance and Retention of Indigenous Australian Students. Issues Paper No. 1. Canberra: Closing the Gap Clearing House.

Rogers, C. (1969) Freedom to Learn. Columbus, OH: Charles E. Merrill.

Smyth, J., Down, B. \& McInerney, P. (2010) 'Hanging in with Kids' in Tough Times: engagement in contexts of educational disadvantage in the relational school. New York: Peter Lang.

Te Riele, K. (2012a) Learning Choices: a map for the future. Report to the Dusseldorp Skills Forum. Melbourne: Victoria Institute for Education, Diversity and Lifelong Learning.

Te Riele, K. (2012b) Negotiating Risk and Hope: a case study of alternative education for marginalized youth, in W. Pink (2012) Schools for Marginalized Youth, pp. 31-79. New York: Hampton Press.

Te Riele, K. (2014) Putting the Jjigsaw Together: flexible learning programs in Australia. Final Report. Melbourne: Victoria Institute for Education, Diversity and Lifelong Learning.

Thomson, P. (2014) What's the Alternative? Effective Support for Young People Disengaging from the Mainstream. Nottingham: Prince's Trust, University of Nottingham.

Wilson, K., Stemp, K. \& McGinty, S. (2011) Re-engaging Young People with Education and Training: what are the alternatives?, Youth Studies Australia, 30(4), 32-39.

GEORGE MYCONOS (corresponding author) is Research Fellow at the Research and Policy Centre, Brotherhood of St Laurence, Fitzroy, Australia. George researches into how emerging alternative education programs assist disengaged young people to gain education and training, and how these programs, along with Australia's vocational training system, cater for disadvantaged students. He has also researched values education, faith-based schools, and the role of intercultural dialogue in secondary schools. His doctoral research focused on theories of globalisation, labour history, and changing forms of global governance. Correspondence: gmyconos@bsl.org.au

JOSEPH THOMAS is a PhD Candidate at the College of Business, Law \& Governance, James Cook University, Townsville, Queensland, Australia. Joseph's $\mathrm{PhD}$ research queries neo-liberal processes in Australia's flexible learning sector. His work considers the influence of the neo-liberal valuation paradigm upon educational goal setting, program design, beneficiary selection, 
and program cycle management. Joseph's research also utilises matching estimator techniques to strengthen the empirical basis for educational policy making in Australia. Correspondence: joseph.thomas1@jcu.edu.au

KIMBERLEY WILSON is a postdoctoral research fellow at the Australian Aboriginal \& Torres Strait Islander Centre, James Cook University, Townsville, Queensland, Australia. Dr Wilson is currently a postdoctoral fellow on the ARC Linkage project, 'Gauging the Value of Flexible Learning Options for Disenfranchised Youth and the Wider Australian Community'. She has published widely around the topic of more effectively engaging youth in education through a responsive and flexible curriculum approach. Correspondence: kimberley.wilson@jcu.edu.au

KITTY TE RIELE is Professorial Research Fellow in the Victoria Institute for Education, Diversity and Lifelong Learning at Victoria University, Melbourne, Australia, and a Chief Investigator on the project informing this article. Her recent books include Interrogating Conceptions of 'Vulnerable Youth' in Theory, Policy and Practice (Sense, 2015, co-edited with Radhika Gorur) and Ethics and Education Research (SAGE, 2014, co-authored with Rachel Brooks and Meg Maguire).Correspondence: kitty.teriele@vu.edu.au

LUKE SWAIN is a researcher in Inclusive Education at the Brotherhood of St Laurence's Research and Policy Centre, Fitzroy, Australia. His research areas include participation in flexible learning programs for disenfranchised young people, and particularly regarding participation in vocational education. Correspondence: luke.swain@bsl.org.au 